\title{
Pathogeneses of respiratory infections with virulent and attenuated vaccinia viruses
}

\author{
Daisuke Hayasaka, Francis A Ennis and Masanori Terajima*
}

Address: Center for Infectious Disease and Vaccine Research, University of Massachusetts Medical School, Worcester, MA 01655, USA

Email: Daisuke Hayasaka - dhay@tmin.ac.jp; Francis A Ennis - Francis.Ennis@umassmed.edu;

Masanori Terajima* - Masanori.Terajima@umassmed.edu

* Corresponding author

Published: 27 February 2007

Virology Journal 2007, 4:22 doi:10.1 186/1743-422X-4-22

This article is available from: http://www.virologyj.com/content/4/I/22

(c) 2007 Hayasaka et al; licensee BioMed Central Ltd.

This is an Open Access article distributed under the terms of the Creative Commons Attribution License (http://creativecommons.org/licenses/by/2.0), which permits unrestricted use, distribution, and reproduction in any medium, provided the original work is properly cited.
Received: 27 December 2006

Accepted: 27 February 2007

\begin{abstract}
Background: Respiratory infection with the neurovirulent vaccinia virus (VV) strain Western Reserve (WR) results in an acute infection of the lung followed by dissemination of the virus to other organs and causes lethality in mice. The mechanisms of lethality are not well-understood. In this study, we analyzed virus replication and host immune responses after intranasal infection with lethal and non-lethal doses of $\mathrm{VV}$ using the WR strain and the less virulent Wyeth strain.
\end{abstract}

Results: The WR strain replicated more vigorously in the lung and in the brain than the Wyeth strain. There were, however, no differences between the virus titers in the brains of mice infected with the higher lethal dose and the lower non-lethal dose of WR strain, suggesting that the amount of virus replication in the brain is unlikely to be the sole determining factor of lethality. The WR strain grew better in primary mouse lung cells than the Wyeth strain. Lethal infection with WR strain was associated with a reduced number of lymphocytes and an altered phenotype of the $T$ cells in the lung compared to non-lethal infections with the WR or Wyeth strains. Severe thymus atrophy with a reduction of CD4 and CD8 double positive T cells was also observed in the lethal infection.

Conclusion: These results suggest that the lethality induced by intranasal infection with a high dose of the WR strain is caused by the higher replication of virus in lung cells and immune suppression during the early phase of the infection, resulting in uncontrolled virus replication in the lung.

\section{Background}

Vaccinia virus (VV) is a member of the Poxviridae, which constitute a large family of enveloped DNA viruses and replicate entirely in the cytoplasm of the infected cells with a linear double-stranded DNA genome of 130-300 kilo base pairs [1]. Poxviruses have a broad range of eukaryotic hosts including mammals, birds, reptiles and insects $[2,3]$ and can grow in many cell lines in vitro. Some poxviruses are causative agents of human diseases.
Variola virus caused a deadly human disease smallpox until its global eradication in $1977[1,4,5]$, in which VV was used as a vaccine. Other poxviruses causing human diseases are molluscum contagiosum virus and the zoonotic monkeypox virus $[6,7]$. Notably, variola and monkeypox viruses are transmitted to humans by respiratory route, whereas molluscum contagiosum virus is mainly transmitted through the skin. Variola and monkeypox viruses cause systemic infections with high levels 
of lethality, but the details of their pathogenesis are not well-understood.

Intranasal inoculation of different $\mathrm{VV}$ strains in mice shows different levels of virulence and only neurovirulent strains cause lethality [8]. Western Reserve (WR) strain was generated by intracerebral mouse passages, and an intranasal inoculation results in an acute infection of the lung followed by dissemination of the virus to various organs [8-11]. Intranasal infection with a low dose of WR strain induces an inflammatory infiltrate in the lung, and the virus was cleared 10 to 15 days after infection [10]; however, infection with a high dose of WR strain caused lethality, which has been used as a challenge model to study the effect of antiviral drugs, immune IgG, soluble viral proteins and other vaccine strains [9,12-20]. In one report intranasal infection with the WR strain caused pneumonia showing severe alveolar edema and acute necrotizing bronchiolitis and peribronchiolitis as well as neutrophilic infiltrates in the interstitium of the lung [21]. The mechanisms of lethality in mice infected with the lethal dose of WR strain are, however, not well-understood.

In this study, we focused on the differences in virus replication and host immune responses between lethal and non-lethal respiratory infections with VV. We used two VV strains; neurotropic virulent WR strain and the less virulent Wyeth strain. Although BALB/c mice are frequently used for intranasal challenge of vaccinia virus $[10,22]$, we used the C57BL6/J strain of mouse in these experiments for two reasons. One is that most knockout mice lacking genes involved in immune responses have been made with C57BL6/J genetic background. The other is that we and one other group have characterized cellular immune responses, especially $\mathrm{CD} 8^{+} \mathrm{T}$ cell responses, to vaccinia virus in C57BL6/J mice $[23,24]$, when this study was planned. Infection of C57BL/6J mouse with a high dose $\left(10^{6}\right.$ p.f.u. (plaque-forming units)) of the WR strain was lethal, whereas a high dose $\left(10^{6}\right.$ p.f.u.) of Wyeth strain and a lower dose ( $10^{4}$ p.f.u.) of WR strain were not lethal. The WR strain replicated and produced higher titers of virus in the lung and the brain compared to the Wyeth strain. There was, however, no difference between the virus titers in brains of mice infected with the high or low dose of WR strain. Lethal infection with WR strain resulted in fewer lymphocytes and an altered phenotype of T cells in the lung compared to non-lethal infection and uninfected controls, and induced severe thymus atrophy with a marked reduction of $\mathrm{CD} 4$ and $\mathrm{CD} 8$ double positive (DP) T cells.

\section{Results}

Virulence of WR and Wyeth strains by intranasal infection Adult female C57BL6/J mice were inoculated with various doses of the WR and Wyeth strains intranasally. Weight change and survival of infected mice were recorded daily. Inoculation with higher doses $\left(10^{6}\right.$ p.f.u. and $10^{5}$ p.f.u. $)$ of the WR strain induced rapid and severe weight loss, which became obvious at 3 days post-infection (Fig. 1A), and most of mice died at 7-10 days post-infection (with $10^{6}$ p.f.u. all mice died by 8 days post-infection) (Fig. 1B). Lower doses $\left(10^{4}\right.$ p.f.u. and $10^{3}$ p.f.u.) of the WR strain caused mild weight loss, and all mice survived. These mice recovered their weight after 6-8 days post-infection (Fig. $1 \mathrm{~A})$. The $50 \%$ lethal dose $\left(\mathrm{LD}_{50}\right)$ of WR strain was calculated as $4.2 \times 10^{4}$ p.f.u., which is similar to the $\mathrm{LD}_{50}$ reported for BALB/C mouse [22]. Wyeth strain did not kill mice (Fig. 1B) or cause weight loss (Fig. 1A) even when $10^{6}$ p.f.u. of the virus was inoculated.

\section{Virus replication in the lung and the brain}

We compared virus replication in the lung and the brain. It had been reported that after intranasal inoculation, virus was recovered from various organs in mice, but higher titers of the virus were detected in the lung and the trachea $[10,22]$. Since WR strain is neurotropic, we also measured virus titers in the brain.

In the lung (Fig. 2A), lethal infection with the WR strain $\left(10^{6}\right.$ p.f.u. $)$ resulted in a rapid increase of virus titer at 1 day post-infection and the virus titer continued to increase until mice died at 7-8 days post-infection. In non-lethal infection with the WR strain ( $10^{4}$ p.f.u.), the virus titer in the lung increased at 1 day post-infection, reached maximum at 3 days post-infection, started to decline 7 days post-infection, and the virus was not detected at 18 days post-infection. In mice infected with Wyeth strain $\left(10^{6}\right.$ p.f.u.), the virus titer in the lung also reached the maximum at 3 days post-infection, but the titer was much lower, and virus was cleared earlier.

The virus titers in the brain showed the same kinetics for the lethal infection with WR strain $\left(10^{6}\right.$ p.f.u.) and the non-lethal infection with WR strain ( $10^{4}$ p.f.u.) (Fig. $\left.2 B\right)$. It reached maximum at 5 days post-infection. In the nonlethal infection the virus titer was still high at 10 days post-infection, and the virus was not eliminated at 18 days post-infection, when mice were recovering their weight (Fig. 1A). Therefore, the virus titer in the brain is unlikely to be the sole determining factor of the lethality. In mice infected with the Wyeth strain $\left(10^{6}\right.$ p.f.u. $)$, virus titer in the brain also reached maximum at 5 days post-infection, but the titer was much lower, and the virus was cleared at 10 days post-infection (Fig. 2B). 
A

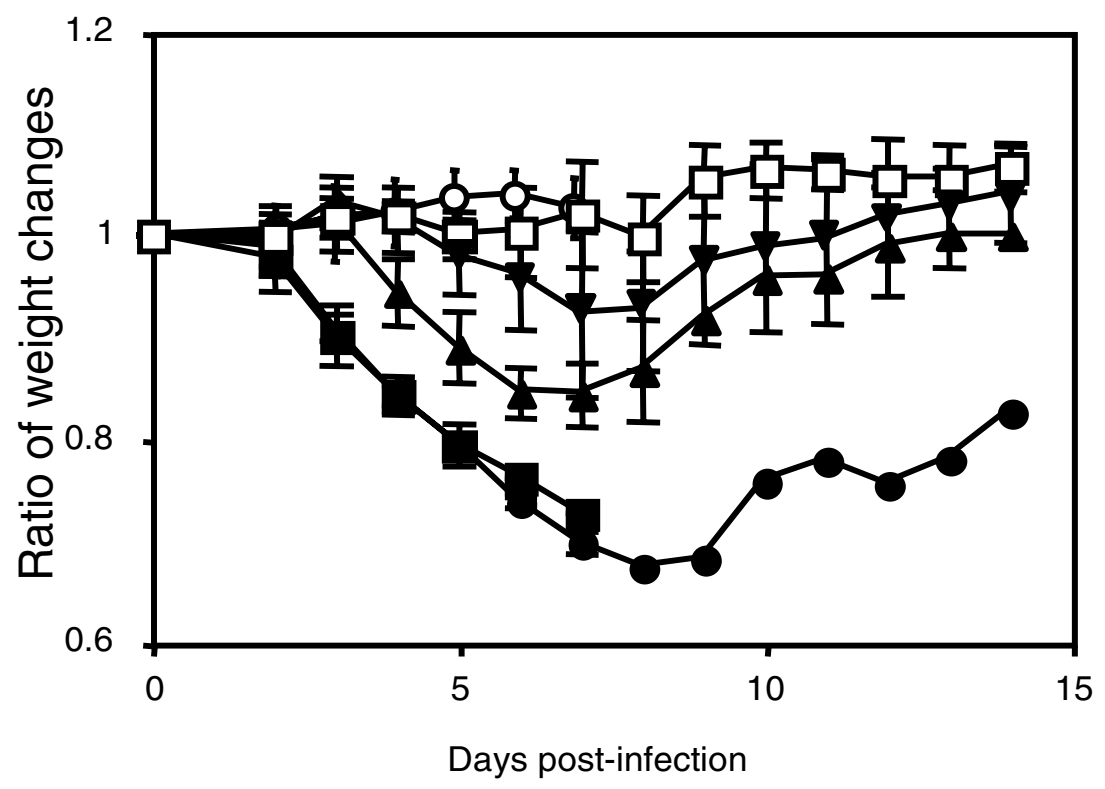

WR $10^{6} \bigcirc$ WR $10^{5} \Delta$ WR $10^{4} \nabla$ WR $10^{3} \square$ Wyeth $10^{6}$ O uninfected



Figure I

Virulence of WR and Wyeth VV strains in C57BL6/J mice after intranasal infection. Groups of five mice were infected with $10^{6}(\mathbf{\square}), 10^{5}(\mathbf{O}), 10^{4}(\mathbf{\Delta})$ and $10^{3}(\nabla)$ p.f.u. of WR strain or $10^{6}(\square)$ p.f.u. of Wyeth strain, or uninfected $(O)$. (A) Time course of the average body weight change of each group is presented. The average weight at day 0 is set as I. The error bars indicate the standard deviations. (B) Survival curve of the infected mice in each group. 




B


Figure 2

Virus titers in the lungs (A) and the brains (B) of the infected mice. Groups of three to five mice were infected with $10^{6}(\square)$ and $10^{4}(\boldsymbol{\Delta})$ p.f.u. of WR and $10^{6}$ p.f.u. ( $\left.\square\right)$ of Wyeth intranasally for each time point, and their lungs and brains were analyzed at various time points post-infection. Titers were calculated as p.f.u./mg tissue for the lung and the brain. The error bars indicate the standard deviations. The data of titers in lungs at 18 days post-infection was under detection level (not plotted in graph A).

\section{Virus replication in cultured mouse lung cells}

In vivo data showed that the WR strain reached higher titers in the lung than the Wyeth strain (Fig. 2A), indicating that virus replication in lung cells were different between WR and Wyeth strains. To compare the replication of WR and Wyeth strains in lung cells, we examined virus replication in primary cultures of mouse lung cells. Primary kidney cells were also used for comparison. When these cells were infected at an m.o.i. (muliplicity of infection) of 0.01 , both WR and Wyeth strains grew well (Fig. 3A). In lung cells, however, the WR strain grew about 400 times better than the Wyeth strain at 48 hours post-infection, whereas in kidney cells the difference was about 20 times (Fig. 3B). When mouse lung endothelial cells (MLECs) were infected, only the WR strain grew (Fig. 3A,B). In another set of experiments, to reduce the influence of cellto-cell spread eliminate the influences of cell-to-cell spread, the cells were infected at an m.o.i. of 1 , and similar results were obtained (Fig. 3A,B). These results show that the WR strain replicated more efficiently in lung cells and lung endothelial cells than the Wyeth strain.

To examine cell-to-cell virus spread in more detail, we compared the plaque formation and the morphology of VV-infected cells. WR strain formed larger plaques and produced many comets on Vero E6 and EA.hy926 cell monolayers at 3 days post-infection (Fig. 4A). In contrast, the Wyeth strain formed smaller plaques and did not produce comets (Fig. 4A). The Wyeth strain induced syncytium formation in CV-1 cells, whereas the WR strain did not (Fig. 4B). These data suggest that cell-to-cell spread is also different between WR and Wyeth strains.

Wyeth strain did not alter the morphology of primary mouse lung cells, whereas the WR strain induced some cytopathic effect (CPE) (Fig. 4B). CPE was not apparent on MLECs infected by either strain (Fig. 4B). In mouse primary kidney cells, the WR strain induced typical CPE and the Wyeth strain formed syncytia similar to CV-1 cells (Fig. 4B). These observations suggest that there may be differences in the replication and dissemination in mouse lungs in vivo at an early phase of infection.

\section{Lymphocytes in the lung}

Virus replication in the lung was suppressed at 5 days post-infection in mice inoculated with a non-lethal dose of WR and the Wyeth strains, while the virus titer in the lung continued to increase in mice infected with the lethal dose of WR until death of the mice (Fig. 2A). We analyzed immune responses at this early phase of the infection focusing on $\mathrm{CD}^{+}$and $\mathrm{CD} 8^{+} \mathrm{T}$ cells and NK cells.

At 5 days post-infection the proportion of lymphocytes in the total lung cells markedly decreased in mice given the lethal infectious dose of the WR strain compared to uninfected control mice (Fig. 5A). In contrast, non-lethal infection with WR and Wyeth strains only caused a mild reduction of lymphocytes (Fig. 5A). There were no differences in the percentages of the $\mathrm{CD}^{+}$population (31$37 \%$ ) of lymphocytes among the uninfected controls and lethally or non-lethally infected mice (Fig. 5B). We, however, noticed that there were two subsets of CD3-positive cells that expressed CD3 at a high level (CD3 $3^{\text {high }}$ ) or intermediate level (CD3 ${ }^{\text {int }}$ ) (Fig. 5B). Lethal-infection with the WR strain increased the proportion of CD3 $3^{\text {int }}$ up to $13.6 \%$ 
A
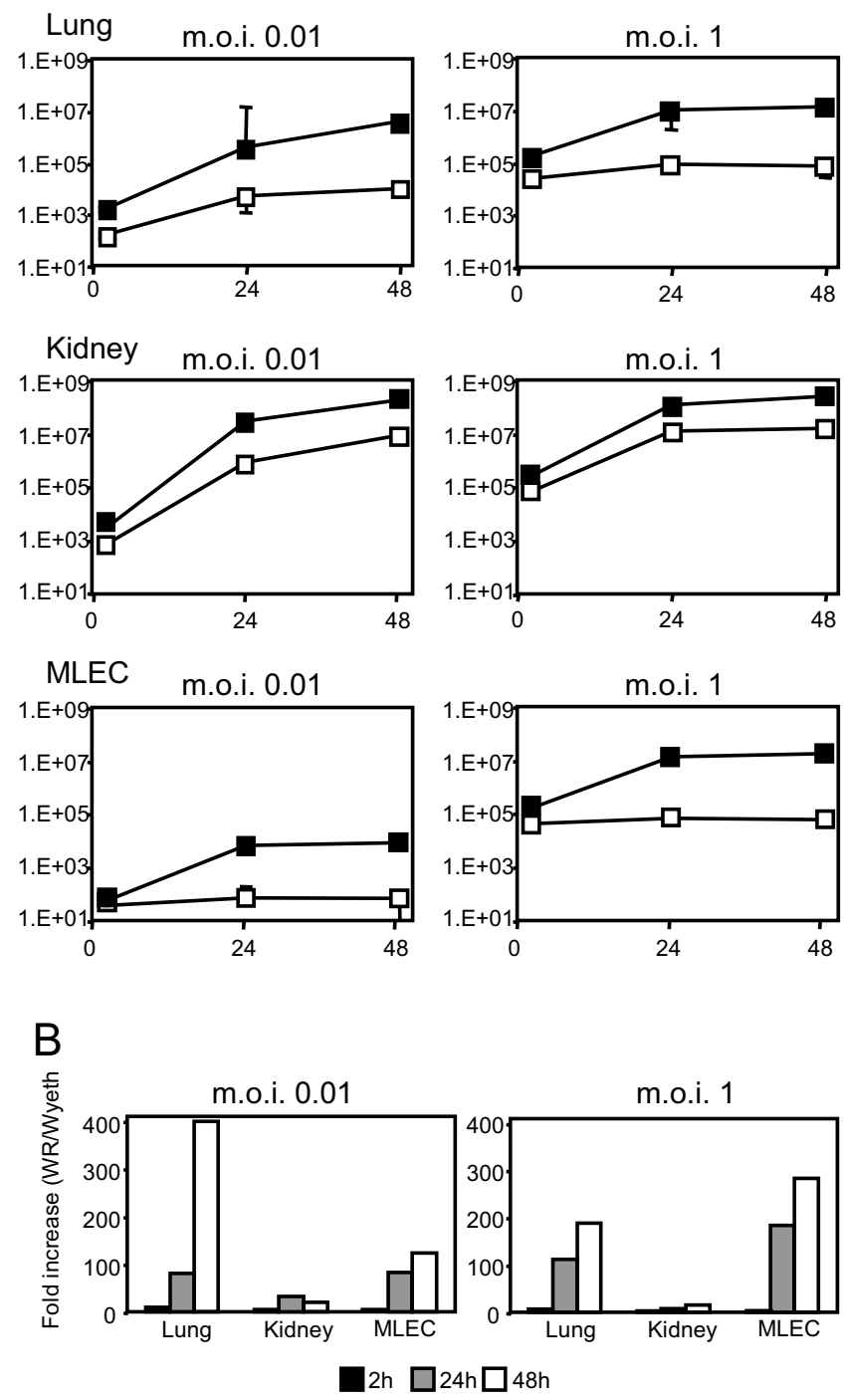

Figure 3

Virus replications in primary mouse lung and kidney cells and MLEC after infection with WR and Wyeth strains at an m.o.i. of $\mathbf{0 . 0 I}$ and I. (A) Virus titers of WR $(\square)$ and Wyeth $(\square)$ strains in cells were determined at 2, 24 and $48 \mathrm{~h}$ post-infection. Titers are shown as p.f.u./well in log scale. The error bars indicate the standard deviations from triplicate samples. (B) Fold increase of WR titers compared to Wyeth titers at 2 (black bar), 24 (gray bar) and 48 (white bar) $h$ post-infection.

compared to $3.49 \%$ of the uninfected control group (Fig. 5B). Non-lethal infection with WR and Wyeth did not induce a significant increase of this subset (Fig. 5B). CD4 expression in the $\mathrm{CD} 3^{\text {int }}$ cells was higher than in the CD3high cells (Fig. 5C). Therefore, the majority of the CD $3^{\text {int }}$ cells were CD4high $C D 8^{-}$cells, whereas CD3 ${ }^{\text {high }}$ cells consisted of CD4 int CD8- and CD4- CD8+ cells (Fig. 5C). As the result, a proportion of $\mathrm{CD} 3$ int $\mathrm{CD} 44^{\text {high }} \mathrm{CD} 8^{-}$lymphocytes markedly increased in lethal-infection with the WR strain $(23.5 \%)$ compared to uninfected controls $(4.4 \%)$ at 5 days post-infection (Fig. 5D).

The percentage of $\mathrm{NK}(\mathrm{NK}+\mathrm{CD} 3-)$ lymphocytes in the lung declined $(9.17 \%)$ in lethal infection at 5 days post-infection compared to the uninfected control (14\%), whereas non-lethal infection increased the proportion of NK cells (25.6\% and 27.3\%) (Fig. 6).

These results indicate that the decrease of lymphocytes including T cells and NK cells and the alterations of the T cell phenotypes in the lung at the early phase of infection may be the reasons why virus replication was not suppressed in the lungs of mice with the lethal infection by the WR strain.

\section{Atrophy of thymus in mice inoculated with the WR strain} In addition to the decreased lymphocytes in the lung, intranasal inoculation with a lethal dose of WR strain induced severe thymus atrophy in C57BL/6J mice (Fig. 7A). The number of thymocytes decreased dramatically by 3 days post-infection compared to uninfected mice (Fig. $7 \mathrm{~B})$. This reduction was associated with a loss of CD4+CD8+ DP cells (Fig. 7D). Non-lethal infection with WR reduced the size of the thymus to some extent (Fig. 7A). The number of thymocytes decreased to about a half of the thymocytes in the uninfected mouse at 5 days postinfection, reached a nadir at 10 days post-infection, and then started to recover (Fig. 7B). The proportion of $\mathrm{CD} 4{ }^{+} \mathrm{CD}^{+}+\mathrm{DP}$ cells was not different at 5 days post-infection (73.2\%), but dropped to $26 \%$ at 10 days post-infection (Fig. 5D). The degree of the decrease of CD4+CD8+ DP cells in the non-lethal infection was not as dramatic as in the lethal infection. Infection with the Wyeth strain did not change the size of the thymus (Fig. 7A) or the number of thymocytes by 5 days post-infection (Fig. 7B). The number of thymocytes started to decline after that (Fig. $7 \mathrm{~B})$, but the proportion of $\mathrm{CD} 4+\mathrm{CD} 8+\mathrm{DP}$ cells stayed unchanged (Fig. 7D).

Virus was recovered from the thymi of mice infected with the lethal dose of WR at 3 and 5 days post-infection (Fig. $7 \mathrm{C})$. In contrast, the virus titers in the thymi in non-lethal infection were mostly below detection levels (Fig. 7C).

\section{Discussion}

In this study, we analyzed virus replication and host immune responses in lethal and non-lethal VV infections in mice. We used two VV strains; the virulent WR strain and the less virulent Wyeth strain. Infection of C57 BL/6 mouse with a high dose $\left(10^{6}\right.$ p.f.u.) of the WR strain was lethal, whereas a high dose $\left(10^{6}\right.$ p.f.u. $)$ of the Wyeth strain 
A

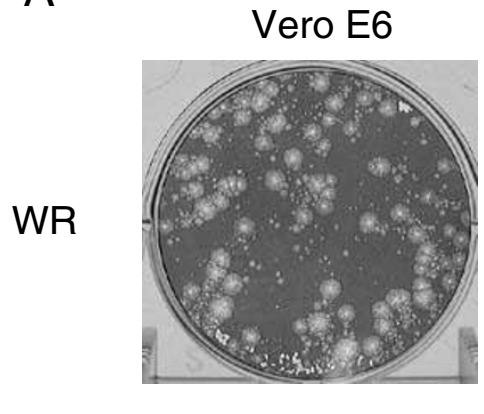

EA.hy926
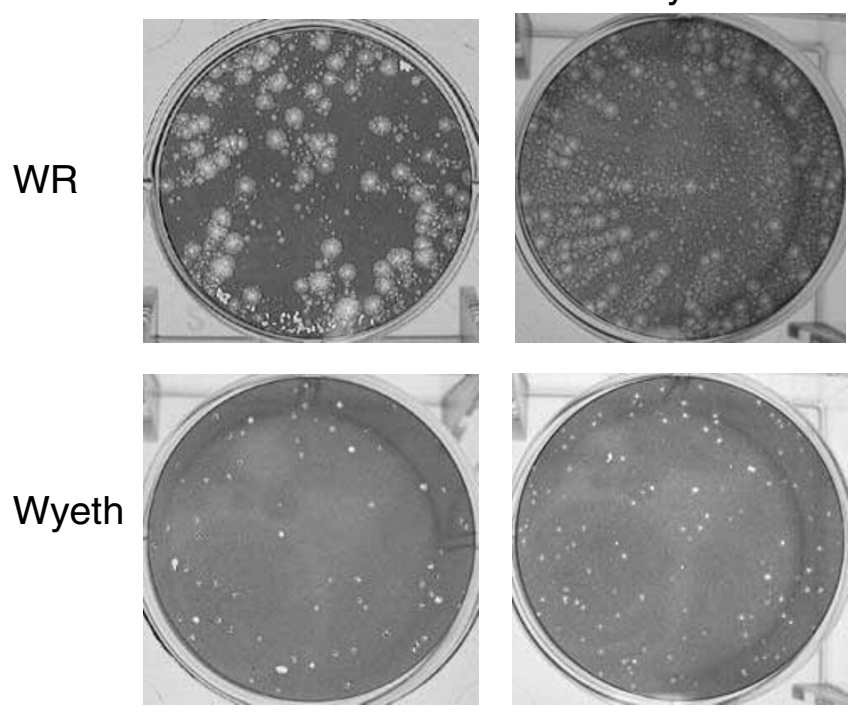

B

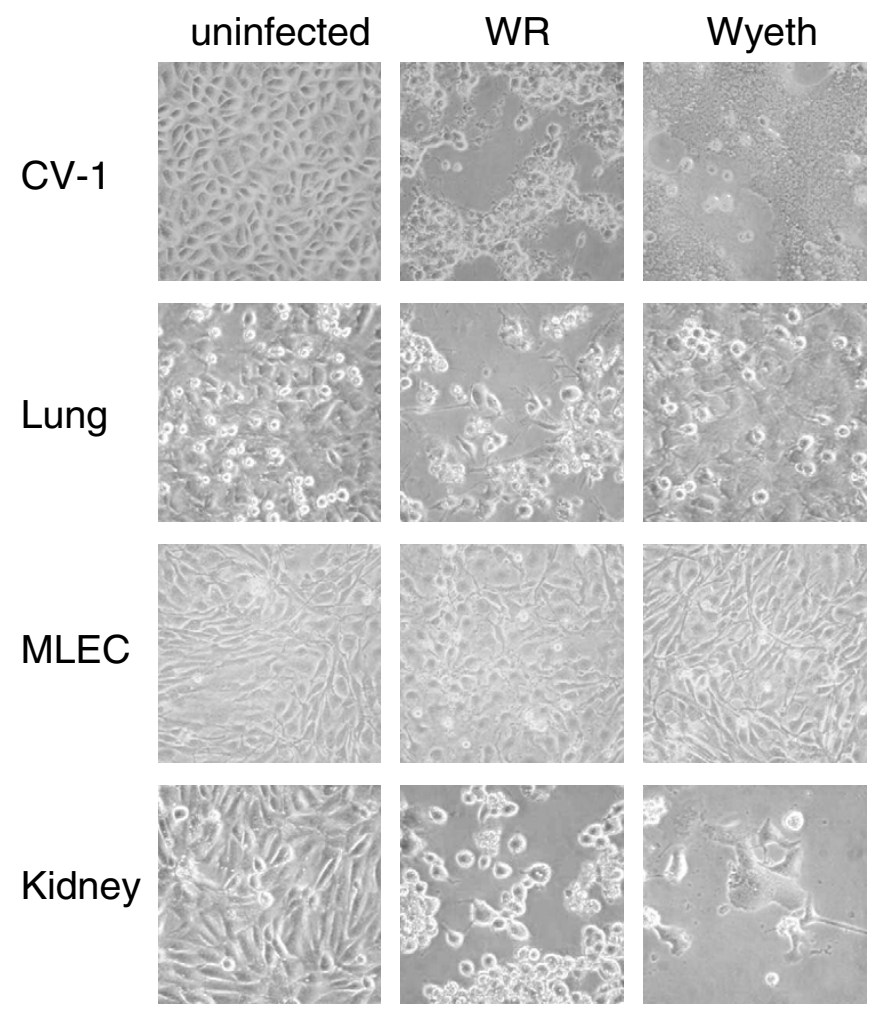

\section{Figure 4}

Morphological changes of cell cultures infected with WR and Wyeth strains at 3 days post-infection. (A) Plaque formation in Vero E6 and EA.hy926 cells. (B) Morphological changes of CV-I, primary mouse lung cells (Lung), MLEC and primary mouse kidney cells (Kidney) at $200 \times$ magnification. Cells were infected with WR or Wyeth strains at m.o.i. I and observed after 2 days post-infection. 
A
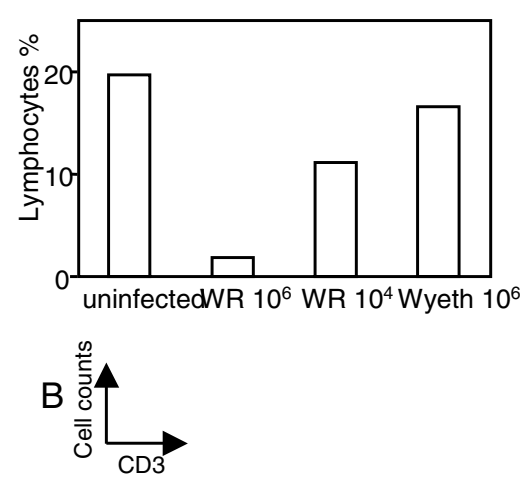

uninfected
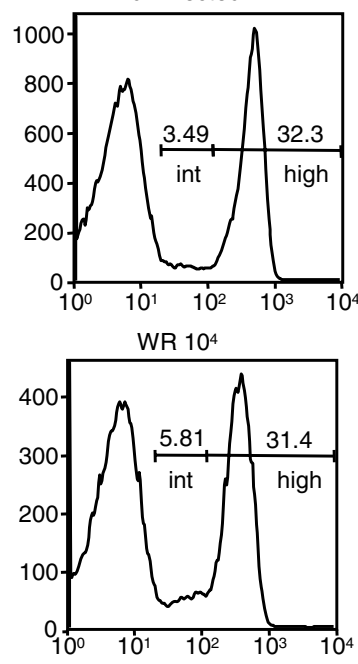

C
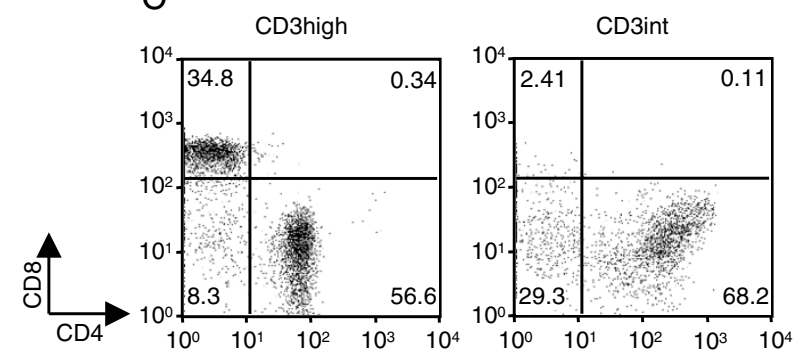

D
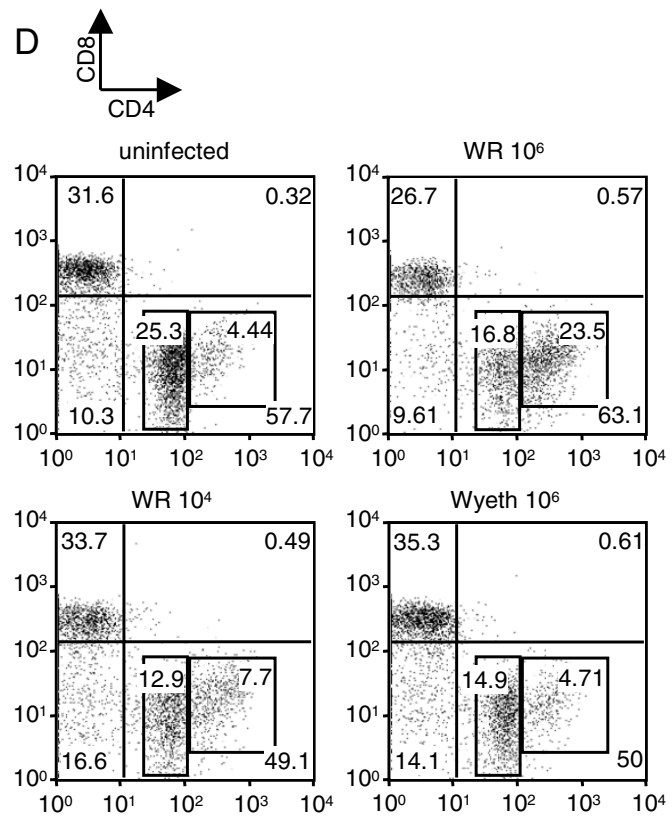

\section{Figure 5}

Characterization of $\mathbf{T}$ lymphocytes in the lung at $\mathbf{5}$ days post-infection. Mice were intranasally infected with $10^{6}$ p.f.u. or $10^{4}$ p.f.u. of WR or $10^{6}$ p.f.u. of Wyeth strain. Cells were isolated from lungs and stained for T cell specific markers CD3, CD4 and CD8. (A) The percentage of lymphocytes in total lung cells isolated from uninfected control and infected mice. (B) Histograms of CD3 expression in lymphocytes from the lung. The percentages of CD3 intermediate (int) and CD3 high (high) subsets are shown in each histogram. (C) CD4 and CD8 expressions in CD3int and CD3high subsets. Data are representative of the lymphocyte subsets obtained from uninfected mice lungs. (D) CD4 and CD8 expressions in CD3 positive cells (CD3int and CD3high) from uninfected control and infected mice lungs. The percentages of CD4 high and CD4 intermediate are shown in each diagram.

or a low dose ( $10^{4}$ p.f.u.) of the WR strain were not lethal. Replication of virus in the lung, but not in the brain, correlated with lethality. The WR strain is known to cause encephalitis after intracranial inoculation $[22,25]$. We, however, did not observe neurological symptoms in any of the infected mice, and think it unlikely that encephalitis caused death of the mice infected with a high dose of the WR strain by the respiratory route.

The lethal infection with WR strain was associated with a decrease of the number of T cells and NK cells in the lung and with an altered phenotype of T cells compared to uninfected controls and non-lethal infections. We used isoflurane to anesthetize mice before intranasal inoculation for consistent administration of the inoculum into the airway. Isoflurane is known to inhibit interferon stimulation of NK cells in mice $[26,27]$. It was also reported that mean white blood cell counts in circulation decreased in mice after exposure to isoflurane anesthesia [28]. In our experiments uninfected control mice were also anesthetized with isoflurane before inoculation of CV-1 cell lysate. Therefore, we interpret the observed decrease of the number of T cells and NK cells in the lung of lethally infected mice (when compared to uninfected controls and non-lethal infections) is due to viral infection, although 

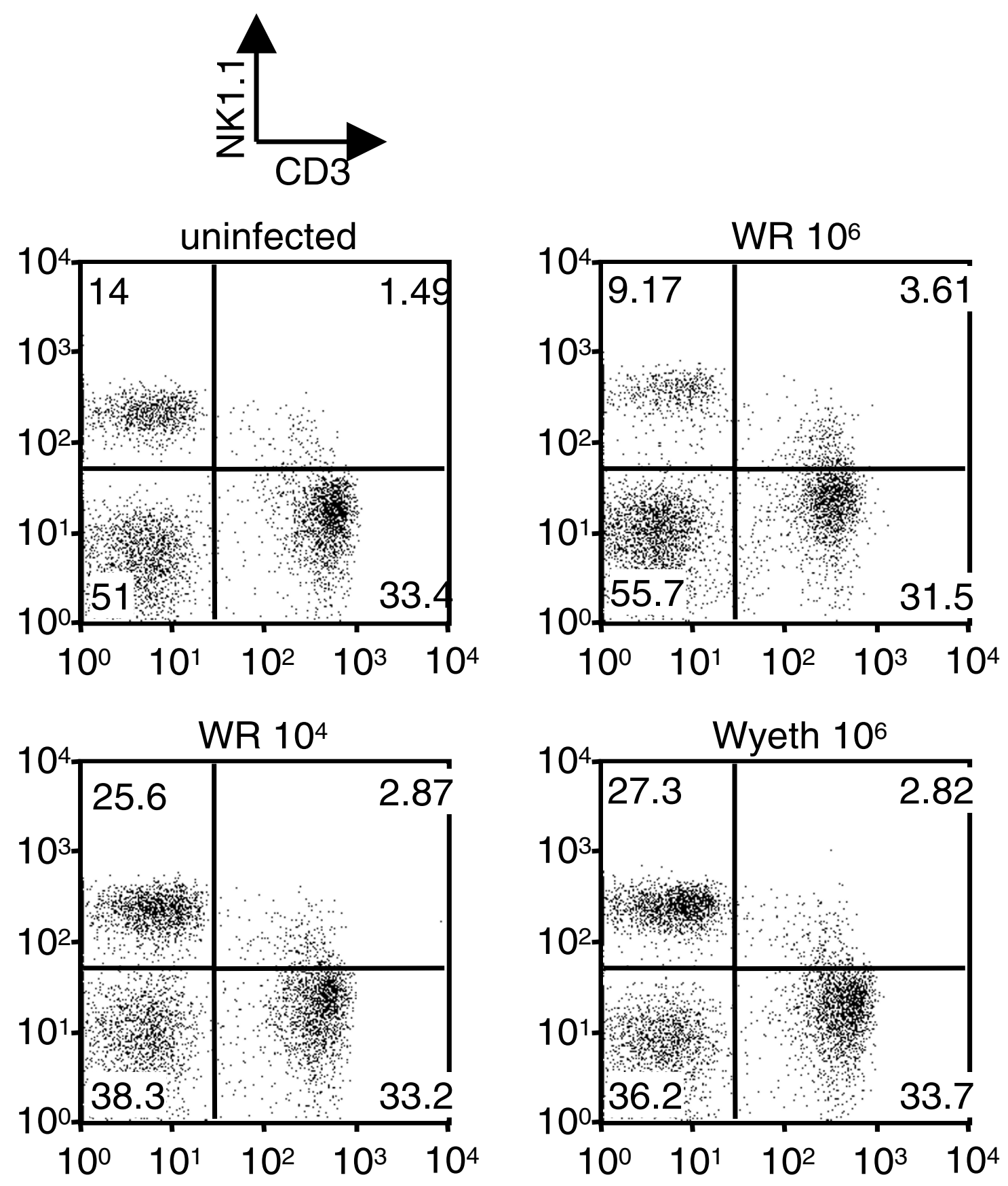

Figure 6

Characterization of infiltrating NK cells in the lung at 5 days post-infection. Mice were intranasally infected with $10^{6}$ p.f.u. or $10^{4}$ p.f.u. of WR or $10^{6}$ p.f.u. of Wyeth. Cells isolated from lungs were stained with mAbs for NKI.I and CD3. 
A

uninfected

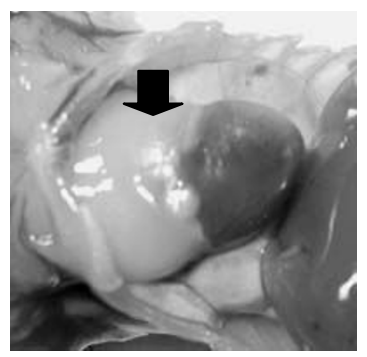

WR $10^{4}$

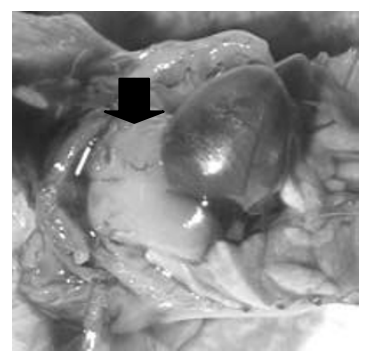

WR $10^{6}$



Wyeth $10^{6}$



D

\section{Day 5}
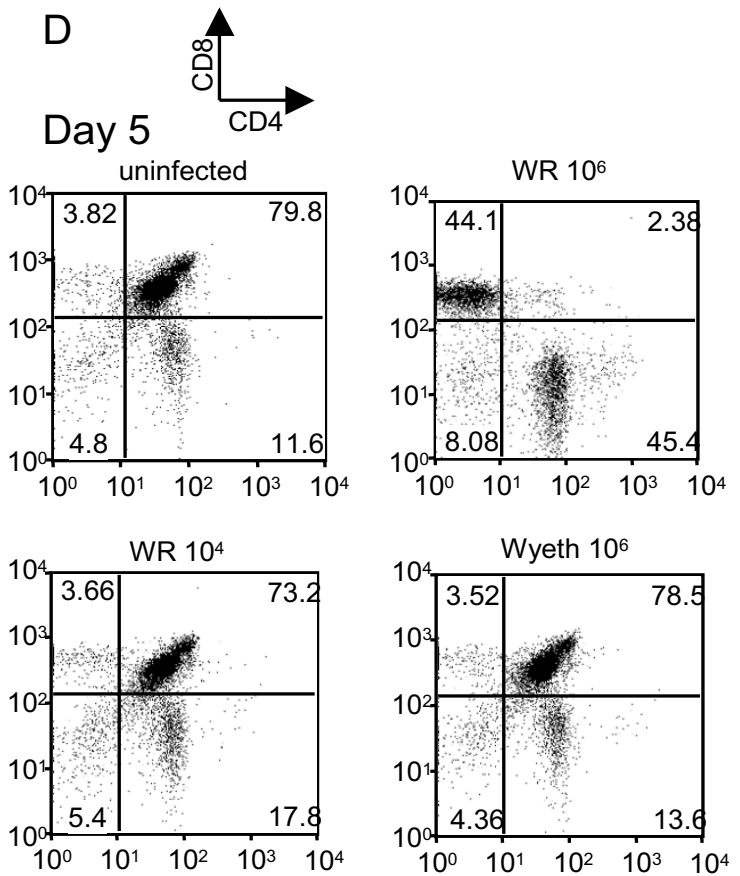



Day 10


Figure 7

Thymus atrophy in mice infected with WR and Wyeth strains. (A) Pictures of the thymus in mice infected intranasally with $10^{6}$ p.f.u. or $10^{4}$ p.f.u. of WR or $10^{6}$ p.f.u. of Wyeth at 5 days post-infection. Arrows indicate the thymi. (B) The numbers of thymocytes from mice infected with WR and Wyeth strains at 3 (white bar), 5 (light gray bar), 10 (dark gray bar) and 18 (black bar) days post-infection. Thymocyets were pooled from groups of three mice and counted. Data are shown as the average numbers of thymocytes per mouse. The dotted line is the average number of thymocytes from uninfected mice. ND; not determined. (C) Virus titers in thymus of mice infected with WR and Wyeth strains at 3 (white bar), 5 (light gray bar), and I0 (dark gray bar) days post-infection. Titers are shown as p.f.u. per organ in log scale. The error bars indicate the standard deviations in triplicate samples. The dotted line indicates the detection limit. ND; not determined. (D) CD4 and CD8 expressions of thymocyets from mice infected with WR and Wyeth strains at 5 (upper five panels) and 10 (lower two panels) days postinfection. 
synergistic effect of viral infection and isoflurane cannot be ruled out.

The lethal infection with WR strain also induced severe thymus atrophy resulting in the reduction of $\mathrm{CD} 4{ }^{+} \mathrm{CD} 8^{+}$ $\mathrm{DP} T$ cells in the thymus. These data suggest that lethal infection with the WR strain by the respiratory route induces immune suppression, resulting in uncontrolled virus replication in the lung. Innate immune responses are likely to be very important to limit virus replication in the lung in the early phase of the infection (1-3 days postinfection) for subsequent recovery from $\mathrm{VV}$ infection. In the absence of effective early immune responses, the mice infected with a high dose of WR do not develop effective adaptive immune responses and the high viral burden suppresses the $\mathrm{T}$ cell responses in the lungs and causes severe thymic atrophy.

Intranasal infection with $\mathrm{VV}$ resulted in peak virus titers in the lung at 3-7 days post-infection (Fig. 2). This replication pattern is similar to infection with paramyxoviruses such as respiratory syncytial virus (RSV) and pneumonia virus of mice (PVM), in which virus titers in the lung peak at 4-5 days post-infection [29-31]. In contrast, other respiratory viruses, such as influenza and SARS viruses, rapidly replicate in the lung after intranasal infection and the virus titers reached a peak at 1-2 days post-infection [3234]. Although RSV has direct cytopathic effects on the respiratory epithelium, host immune responses are more important factors in disease pathogenesis [35]. In lethal intranasal infection with $\mathrm{VV}$, in contrast, there is a marked decrease in lymphocytes in the lung. T cells are key effectors of virus clearance in mice infected with various viruses via respiratory route [36]. Immune suppression of $\mathrm{T}$ cells is considered to be an immune evasion strategy, observed in several respiratory virus infections. For example, PVM and RSV suppressed T cell effecter functions in the lung $[37,38]$. Adenovirus infection induced $\mathrm{T}$ cells with decreased proliferative ability in the lung and local immunoincompetence by altering DC-T-cell interaction [39]. Infection with highly virulent influenza A strains down-regulated $\mathrm{CD} 8^{+} \mathrm{T}$ cell responses [33]. Since VV has many immunomodulatory proteins [40-42], it is not surprising that high levels of WR VV induced immune suppression in the infected lungs.

We observed that intranasal VV infection induced severe thymus atrophy (Fig. 7). Severe atrophy of the thymus is seen in several infections [43] including acute viral infections, such as rabies [44,45], measles [46,47], mouse hepatitis [48], and Ebola viruses [49]. Although inoculation of ectromelia virus into the food-pad of $\mathrm{BALB} / \mathrm{c}$ mouse is known to cause the necrosis of thymus as well as other lymphatic tissues [50], there has been no description of thymus atrophy in mice induced by respiratory infection with VV. It is not known whether RSV, PVM, adenovirus and influenza A virus cause thymus atrophy when immune suppression of T cells is observed in the lung. The atrophy of the thymus was mainly due to a reduction of immature $\mathrm{CD}^{+}{ }^{+} \mathrm{CD} 8^{+} \mathrm{DP}$. One major consideration regarding thymus atrophy is a rise of glucocorticoid hormone level in the blood, which is induced due to the stress responses to severe infections $[43,44,51,52]$. $\mathrm{CD} 4{ }^{+} \mathrm{CD} 8+\mathrm{DP}$ thymocytes are particularly sensitive to glucocorticoids. In addition, some cytokines, such as tumor necrosis factor- $\alpha$, may also contribute to the thymus atrophy in some infections $[48,53]$. It also has been suggested that infection of the cells in thymus is involved in reducing the number of thymocytes $[43,46-48,54,55]$. In measles and mouse hepatitis virus infections apoptotic depletion of thymocytes is mediated by the infection of thymic epithelial cells [46-48]. In Trypanosoma cruzi infection parasite-derived factors are involved in apoptosis of thymocytes $[43,54,55]$. VV has been found to synthesize steroid hormones with a $3 \beta$-hydroxysteroid dehydrogenase encoded by gene A44L [56]. We did not perform experiments dissecting the mechanisms of the thymus atrophy induced by intranasal VV infection in the lethal infection. However, virus was recovered from the thymus when the thymocyte number was markedly decreasing at days 3 and 5 post-infection in the lethal infection (Fig. 7B and 7C), suggesting that the steroid hormone synthesized by both virus and host may contribute to thymus atrophy as well as the direct effect of virus infection against thymic cells. The VV A44L gene is well conserved among VV strains. In contrast, virus was under the detection limit in the thymi of mice infected with a nonlethal dose of WR when the thymocyte number was at nadir at day 10 post-infection (Fig. 7B and 7C). Further investigation is required to uncover the mechanisms of thymus atrophy induced by respiratory infection with VV. At this point it appears that acute thymus atrophy early in infection may be a component of the lethal outcome.

WR and Wyeth strains differed in the ability to grow in primary cultures of lung and lung endothelial cells, which reflected the in vivo growth of these viruses in the lung. The size of the virus plaques and the ability to form comets were also different between these two strains (Fig. 4A). In addition, the Wyeth strain induced syncytium formation in infected cells, but the WR strain did not (Fig. 4B). Usually cell-cell fusion is not apparent during VV infection in cultured cells, but it appears spontaneously with certain mutants or can be triggered by briefly lowering the $\mathrm{pH}$ [57]. These differences suggest different host-virus interactions in infected lung cells, and in the case of WR infection, a high dose of virus resulted in uncontrolled replication of the virus in the lung. It has been reported that the hemagglutin and serine protease inhibitor 3 are fusion inhibitor proteins and mutants containing a dis- 
ruption of these proteins form syncytia at neutral $\mathrm{pH}$ [5862]. We did not analyze nucleotide differences between WR and Wyeth strains, since the Wyeth strain is not cloned and is genetically heterogeneous, which recent sequencing data of Dryvax (derived from the same New York City Board of Health strain) confirmed (GenBank accession numbers DQ377945, AY313847, AY313848).

\section{Conclusion}

This study suggests that the lethality induced by intranasal infection with a high dose of the WR strain of VV is caused by increased replication of the virus in lung cells and lymphocyte depletion in the lungs and the thymus during the early phase of the infection, resulting in uncontrolled virus replication in the lung. Murine models of respiratory infection with several viruses have been provided useful information about acute and chronic virus respiratory infection, humoral and cellular immune responses, CD4 and CD8 T cell biology, and innate immune responses. We think that VV respiratory infection of the mouse is a useful model not only to understand the pathogeneses of poxviruses but also other respiratory viruses.

\section{Methods \\ Viruses and cells}

Vaccinia virus WR strain was kindly provided by Girish J. Kotwal, Division of Medical Virology, University of Cape Town, Cape Town, South Africa, and William L. Marshall of Department of Medicine, University of Massachusetts Medical School, and the Wyeth strain was kindly provided by Margo A. Brinton of the Department of Biology, Georgia State University, Atlanta, GA, through Ching-Juh Lai of Laboratory of Infectious Diseases, National Institute of Allergy and Infectious Diseases, National Institutes of Health. Viruses were grown in CV-1 cells (ATCC CCL-70) and virus stocks were prepared from cell lysates. CV-1 cells were maintained in Minimum Essential medium (MEM) (Invitrogen, Carlsbad, CA) containing 10\% fetal bovine serum (FBS). A human endothelial cell line, EA.hy926, was kindly provided by Cora-Jean S. Edgell, University of North Carolina. EA.hy926 cells and Vero E6 cells (ATCC CRL-1586) were maintained in Dulbecco's modified Eagle's medium (DMEM) (Invitrogen) containing 10\% FBS. Virus titers were determined by plaque forming assay using CV-1 cells following the standard procedure [63].

\section{Isolation of mouse primary lung and kidney cells}

Primary mouse lung and kidney cells were isolated from female C57BL/6J mice. Lungs and kidneys were removed and diced with scissors. Then, each organ was digested with $1 \mathrm{mg} / \mathrm{ml}$ collagenase A (Roche Diagnostics, Indianapolis, IN) for $45 \mathrm{~min}$, filtered with a $70 \mu \mathrm{m}$ cell strainer (BD Biosciences, Bedford, MA), and the separated cells were grown in DMEM supplemented with 10\% FBS.
MLECs were isolated and grown as previously reported $[64,65]$. Briefly, mouse lung cells were incubated with Dynabeads ${ }^{\circledast}$ M-450 Sheep anti-Rat IgG (Dynal Biotech ASA, Oslo, Norway) coated with MEC13.3 (anti-mouse CD31 rat IgG)(BD PharMingen, San Diego, CA). CD31expressing cells were separated by Dynal MPC-L Magnetic Particle Concentrator (Dynal Biotech ASA, Oslo, Norway) and grown in a gelatin-coated tissue culture flask. One week later, adherent cells were trypsinyzed, and CD102expressing cells were isolated by 3C4 (anti-mouse CD102 rat $\operatorname{IgG})(\mathrm{BD}$ PharMingen)-coated beads and grown in DMEM with $20 \%$ FBS supplemented with $100 \mu \mathrm{g} / \mathrm{ml}$ heparin sodium salt from porcine intestinal mucosa (Sigma-Aldrich, St. Louis, MO) and $100 \mu \mathrm{g} / \mathrm{ml}$ endothelial cell growth supplement (BD Biosciences). Cells were confirmed to express the endothelial specific markers, PECAM (CD31), ICAM-2 (CD102) and VE-cadherin (CD144) by flow cytometric analysis.

\section{Virus inoculation}

4-6 week-old female C57BL/6J mice were purchased from The Jackson Laboratory. Mice were anesthetized with isoflurane and then intranasaly inoculated with various doses $\left(10^{3}\right.$ to $10^{6}$ p.f.u.) of the WR or Wyeth strains, or uninfected CV-1 cell lysate (for control mice) in a total volume of $50 \mu \mathrm{l}$. Mice were observed for disease symptoms and weighed daily. All mice were maintained in the Animal Facility at the University of Massachusetts Medical School, which is regulated by AWA-1995, PHS-1986, MA140-1985 and follows the AAALAC-1965 guidelines.

\section{Virus titration in organs}

Lungs, brains and thymi were taken from mice inoculated with VV at different days post-infection and kept frozen at $-80^{\circ} \mathrm{C}$ until use. Each organ was ground on a $40 \mu \mathrm{m}$ cell strainer (BD Biosciences) in ten volumes of phosphatebuffered saline (PBS) with 10\% FBS and sonicated for 30 seconds six times. Virus titers were determined by plaque forming assays and titers were calculated as p.f.u./mg tissue for the lung and the brain, and p.f.u./total tissue for the thymus.

\section{Virus growth curve in cell culture}

CV-1, Vero E6, primary mouse lung and kidney cells, and MLECs were grown in 6-well plates until cells became confluent. The monolayers were inoculated with VV for 2 hours at indicated multiplicity of infection (m.o.i.). Cells were harvested at different time points after infection and kept at $-80^{\circ} \mathrm{C}$ until use. Cells were resuspended in $100 \mu \mathrm{l}$ of PBS with $10 \%$ FBS and sonicated. Virus titers were determined by plaque forming assay using CV-1 cells and titers were calculated as p.f.u./well. 


\section{Recovery of leukocytes from lungs, thymi and spleens}

Lung leukocytes were isolated from VV-infected mice and uninfected control mice at indicated time points. Lungs were inflated with RPMI medium (Invitrogen) through the trachea and washed with PBS. A pool of lungs from four mice was minced and digested with collagenase A (Roche Diagnostics), and then lung cells were strained with a $70 \mu \mathrm{m}$ cell strainer (BD Biosciences). Live cells were separated from dead cells or debris of lung tissue by centrifugation with Ficoll-Paque (GE Healthcare Bio-sciences AB, Uppsala, Sweden). Thymocytes were also recovered from VV-infected mice and uninfected control mice at indicated time points. A pool of thymocytes or splenocytes from four mice was lysed with RBC lysis buffer (Sigma-Aldrich), and resuspended in RPMI medium.

\section{Flow cytometric analysis of cell-surface antigens}

Lung leukocytes and thymocytes were washed and were blocked with Purified Rat Anti-Mouse CD16/CD32

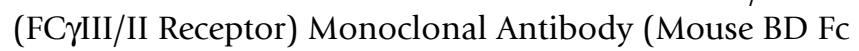
Block)(BD PharMingen) in FACS buffer (PBS containing $0.1 \%$ BSA and $0.1 \%$ sodium azide). Cells were stained with a mixture of different fluorescent-labeled antibodies directed at surface phenotypic markers, CD45, CD3, CD4, CD8a, NK1.1 and CD25 (eBioscience, San Diego, CA), and then fixed with $2 \%$ paraformaldehyde. The stained cells were analyzed by FACSAria (BD Biosciences). Leukocytes were recognized by characteristic size (forward scatter, FSC), granularity (side scatter, SSC) and CD45 expression.

\section{Competing interests}

The author(s) declare that they have no competing interests.

\section{Authors' contributions}

DH, FAE and MT conceived of the study. DH designed and performed the experiments. DH and MT analyzed the results. DH, FAE and MT discussed the results and prepared the manuscript. All authors read and approved the final manuscript.

\section{Acknowledgements}

We thank Girish J. Kotwal, Division of Medical Virology, University of Cape Town, Cape Town, South Africa, William L. Marshall of Department of Medicine, University of Massachusetts Medical School, Margo A. Brinton of Department of Biology, Georgia State University, Atlanta, GA, and ChingJuh Lai of Laboratory of Infectious Diseases, National Institute of Allergy and Infectious Diseases, National Institutes of Health for kindly providing us vaccinia virus WR and Wyeth strains, Cora-Jean S. Edgell of University of North Carolina for providing us the EA.hy 926 cell line, Anuja Mathew, Alan L. Rothman, Joel O'Bryan, and Anita M. Leporati for technical assistance and discussion, Marcia Woda for technical assistance and advice regarding the FACS analyses, and the Animal Facility at the University of Massachusetts Medical School for taking care of our mice. We also thank the Poxvirus Bioinformatics Resource Center [66], database of which we used frequently. This study was supported by the National Institute of
Allergy and Infectious Diseases, National Institutes of Health grant UI9-AI057319 and Contract NOI-Al-25490.

\section{References}

I. Moss B: Poxviridae: the viruses and the replication, p. 28492883. In D.M. Knipe et al. (ed), Fields Virology, 4th ed. In Fields Virology, 4th ed Philadelphia, Pa, Lippincott Williams and Wilkins; 200I:2849-2883.

2. Lefkowitz EJ, Wang C, Upton C: Poxviruses: past, present and future. Virus Res 2006, II7(I): 105-II8.

3. McFadden G: Poxvirus tropism. Nat Rev Microbiol 2005, 3(3):20I-2I3.

4. Fenner F: Smallpox and its eradication. In World Health Organization Geneva ; 1988

5. Bray M, Buller M: Looking back at smallpox. Clin Infect Dis 2004, 38(6):882-889.

6. Hanson D, Diven DG: Molluscum contagiosum. Dermatol Online J 2003, 9(2):2.

7. Di Giulio DB, Eckburg PB: Human monkeypox. Lancet Infect Dis 2004, 4(4): 199.

8. Turner GS: Respiratory infection of mice with vaccinia virus. Gen Virol I 967, I (3):399-402

9. Smee DF, Bailey KW, Sidwell RW: Treatment of lethal vaccinia virus respiratory infections in mice with cidofovir. Antivir Chem Chemother 200I, I 2(I):7I-76.

10. Reading PC, Smith GL: A kinetic analysis of immune mediators in the lungs of mice infected with vaccinia virus and comparison with intradermal infection. J Gen Virol 2003, 84(Pt 8): $1973-1983$.

II. Williamson JD, Reith RW, Jeffrey LJ, Arrand JR, Mackett M: Biological characterization of recombinant vaccinia viruses in mice infected by the respiratory route. J Gen Virol 1990, 71 ( Pt II):276I-2767.

12. Belyakov IM, Earl P, Dzutsev A, Kuznetsov VA, Lemon M, Wyatt LS, Snyder JT, Ahlers JD, Franchini G, Moss B, Berzofsky JA: Shared modes of protection against poxvirus infection by attenuated and conventional smallpox vaccine viruses. Proc Natl Acad Sci U S A 2003, I 00(16):9458-9463.

13. Fogg C, Lustig S, Whitbeck JC, Eisenberg RJ, Cohen GH, Moss B: Protective immunity to vaccinia virus induced by vaccination with multiple recombinant outer membrane proteins of intracellular and extracellular virions. J Virol 2004, 78(19): 10230-10237.

14. Law M, Putz MM, Smith GL: An investigation of the therapeutic value of vaccinia-immune IgG in a mouse pneumonia model. J Gen Virol 2005, 86(Pt 4):991-1000.

15. Meseda CA, Garcia AD, Kumar A, Mayer AE, Manischewitz J, King LR, Golding $\mathrm{H}$, Merchlinsky M, Weir JP: Enhanced immunogenicity and protective effect conferred by vaccination with combinations of modified vaccinia virus Ankara and licensed smallpox vaccine Dryvax in a mouse model. Virology 2005, 339:164-75

16. Reeves PM, Bommarius B, Lebeis S, McNulty S, Christensen J, Swimm A, Chahroudi A, Chavan R, Feinberg MB, Veach D, Bornmann W, Sherman M, Kalman D: Disabling poxvirus pathogenesis by inhibition of Abl-family tyrosine kinases. Nat Med 2005.

17. Smee DF, Bailey KW, Wong MH, Sidwell RW: Effects of cidofovir on the pathogenesis of a lethal vaccinia virus respiratory infection in mice. Antiviral Res 200I, 52(I):55-62.

18. Snyder JT, Belyakov IM, Dzutsev A, Lemonnier F, Berzofsky JA: Protection against lethal vaccinia virus challenge in HLA-A2 transgenic mice by immunization with a single CD8+ T-cell peptide epitope of vaccinia and variola viruses. J Virol 2004, 78(13):7052-7060.

19. Wyatt LS, Earl PL, Eller LA, Moss B: Highly attenuated smallpox vaccine protects mice with and without immune deficiencies against pathogenic vaccinia virus challenge. Proc Natl Acad Sci US A 2004, I OI(13):4590-4595.

20. Yang H, Kim SK, Kim M, Reche PA, Morehead TJ, Damon IK, Welsh RM, Reinherz EL: Antiviral chemotherapy facilitates control of poxvirus infections through inhibition of cellular signal transduction. J Clin Invest 2005, I I 5(2):379-387.

21. Chen HD, Fraire AE, Joris I, Brehm MA, Welsh RM, Selin LK: Memory CD8+ $T$ cells in heterologous antiviral immunity and 
immunopathology in the lung. Nat Immunol 200I, 2(II):1067-1076.

22. Lee MS, Roos JM, McGuigan LC, Smith KA, Cormier N, Cohen LK, Roberts $B E$, Payne $L G$ : Molecular attenuation of vaccinia virus: mutant generation and animal characterization. J Virol 1992, 66(5):2617-2630.

23. Mathew A, Terajima M, West K, Green S, Rothman AL, Ennis FA, Kennedy JS: Identification of murine poxvirus-specific CD8+ CTL epitopes with distinct functional profiles. J Immunol 2005, I 74(4):2212-2219.

24. Tscharke DC, Karupiah G, Zhou J, Palmore T, Irvine KR, Haeryfar SM, Williams S, Sidney J, Sette A, Bennink JR, Yewdell JW: Identification of poxvirus CD8+ $T$ cell determinants to enable rational design and characterization of smallpox vaccines. J Exp Med 2005, 20I(I):95-104.

25. Billings B, Smith SA, Zhang Z, Lahiri DK, Kotwal GJ: Lack of NIL gene expression results in a significant decrease of vaccinia virus replication in mouse brain. Ann N Y Acad Sci 2004 1030:297-302.

26. Markovic SN, Knight PR, Murasko DM: Inhibition of interferon stimulation of natural killer cell activity in mice anesthetized with halothane or isoflurane. Anesthesiology 1993, 78(4):700-706.

27. Markovic SN, Murasko DM: Anesthesia inhibits interferoninduced natural killer cell cytotoxicity via induction of CD8+ suppressor cells. Cell Immunol I993, I 5 I(2):474-480.

28. Jacobsen KO, Villa V, Miner VL, Whitnall MH: Effects of anesthesia and vehicle injection on circulating blood elements in $\mathrm{C} 3 \mathrm{H} /$ HeN male mice. Contemp Top Lab Anim Sci 2004, 43(5):8-I 2.

29. Cook PM, Eglin RP, Easton A): Pathogenesis of pneumovirus infections in mice: detection of pneumonia virus of mice and human respiratory syncytial virus $m R N A$ in lungs of infected mice by in situ hybridization. J Gen Virol 1998, 79 ( Pt 10):24I I-24I7.

30. Jafri HS, Chavez-Bueno S, Mejias A, Gomez AM, Rios AM, Nassi SS, Yusuf M, Kapur P, Hardy RD, Hatfield J, Rogers BB, Krisher K, Ramilo $O$ : Respiratory syncytial virus induces pneumonia, cytokine response, airway obstruction, and chronic inflammatory infiltrates associated with long-term airway hyperresponsiveness in mice. J Infect Dis 2004, I 89( I 0): 1856-1865.

31. Davis IC, Sullender WM, Hickman-Davis JM, Lindsey JR, Matalon S Nucleotide-mediated inhibition of alveolar fluid clearance in BALB/c mice after respiratory syncytial virus infection. Am J Physiol Lung Cell Mol Physiol 2004, 286(I):LI I 2-20.

32. Subbarao K, McAuliffe J, Vogel L, Fahle G, Fischer S, Tatti K, Packard $M$, Shieh W], Zaki S, Murphy B: Prior infection and passive transfer of neutralizing antibody prevent replication of severe acute respiratory syndrome coronavirus in the respiratory tract of mice. / Virol 2004, 78(7):3572-3577.

33. Legge KL, Braciale TJ: Lymph Node Dendritic Cells Control CD8(+) T Cell Responses through Regulated FasL Expression. Immunity 2005, 23(6):649-659.

34. Tumpey TM, Lu X, Morken T, Zaki SR, Katz JM: Depletion of lymphocytes and diminished cytokine production in mice infected with a highly virulent influenza A (H5NI) virus isolated from humans. J Virol 2000, 74(I3):6 I05-6II6.

35. Peebles RS Jr., Graham BS: Pathogenesis of respiratory syncytia virus infection in the murine model. Proc Am Thorac Soc 2005, 2(2): II0-II5.

36. Doherty PC, Topham D, Tripp RA, Cardin RD, Brooks JW, Stevenson PG: Effector CD4+ and CD8+ T-cell mechanisms in the control of respiratory virus infections. Immunol Rev 1997 159:105-117.

37. Claassen EA, van der Kant PA, Rychnavska ZS, van Bleek GM, Easton A], van der Most RG: Activation and Inactivation of Antiviral CD8 T Cell Responses during Murine Pneumovirus Infection. J Immunol 2005, I 75( I 0):6597-6604.

38. Chang J, Braciale T): Respiratory syncytial virus infection suppresses lung CD8+ T-cell effector activity and peripheral CD8+ T-cell memory in the respiratory tract. Nat Med 2002, 8(I):54-60.

39. Thiele AT, Sumpter TL, Walker JA, Xu Q, Chang CH, Bacallao RL, Kher R, Wilkes DS: Pulmonary immunity to viral infection: adenovirus infection of lung dendritic cells renders $T$ cells nonresponsive to interleukin-2. J Virol 2006, 80(4): 1826-1836.

40. Haga IR, Bowie AG: Evasion of innate immunity by vaccinia virus. Parasitology 2005, I30(Suppl):SI I-25.
4I. Seet BT, Johnston JB, Brunetti CR, Barrett JW, Everett H, Cameron C, Sypula J, Nazarian SH, Lucas A, McFadden G: Poxviruses and immune evasion. Annu Rev Immunol 2003, 21:377-423.

42. Smith SA, Kotwal G]: Immune response to poxvirus infections in various animals. Crit Rev Microbiol 2002, 28(3): 149-185.

43. Savino $W$ : The thymus is a common target organ in infectious diseases. PLoS Pathog 2006, 2(6):e62.

44. Cardenas Palomo LF, de Souza Matos DC, Chaves Leal E, Bertho AL, Marcovistz R: Lymphocyte subsets and cell proliferation analysis in rabies-infected mice. J Clin Lab Immunol I995, 46(2):49-6I.

45. Lafon M, Scott-Algara D, Marche PN, Cazenave PA, Jouvin-Marche E: Neonatal deletion and selective expansion of mouse $T$ cells by exposure to rabies virus nucleocapsid superantigen. J Exp Med 1994, 180(4): 1207-1215.

46. Auwaerter PG, Kaneshima H, McCune JM, Wiegand G, Griffin DE: Measles virus infection of thymic epithelium in the SCID-hu mouse leads to thymocyte apoptosis. J Virol 1996, 70(6):3734-3740.

47. Vidalain PO, Laine D, Zaffran Y, Azocar O, Servet-Delprat C, Wild TF, Rabourdin-Combe C, Valentin H: Interferons mediate terminal differentiation of human cortical thymic epithelial cells. J Virol 2002, 76(13):6415-6424.

48. Godfraind C, Holmes KV, Coutelier IP: Thymus involution induced by mouse hepatitis virus $\mathrm{A59}$ in BALB/c mice. J Virol 1995, 69(10):654|-6547.

49. Gibb TR, Bray M, Geisbert TW, Steele KE, Kell WM, Davis KJ, Jaax NK: Pathogenesis of experimental Ebola Zaire virus infection in BALB/c mice. J Comp Pathol 200I, I 25(4):233-242.

50. Buller RM: The BALB/c mouse as a model to study orthopoxviruses. Curr Top Microbiol Immunol 1985, I 22: I 48-I53.

5I. Jondal M, Pazirandeh A, Okret S: Different roles for glucocorticoids in thymocyte homeostasis? Trends Immunol 2004, 25(II):595-600.

52. Ito $M$, Nishiyama $K$, Hyodo $S$, Shigeta $S$, Ito $T$ : Weight reduction of thymus and depletion of lymphocytes of T-dependent areas in peripheral lymphoid tissues of mice infected with Francisella tularensis. Infect Immun 1985, 49(3):8|2-8|8.

53. Chen W, Kuolee R, Austin JW, Shen H, Che Y, Conlan JW: Low dose aerosol infection of mice with virulent type A Francisella tularensis induces severe thymus atrophy and CD4+CD8+ thymocyte depletion. Microb Pathog 2005, 39(56): $189-196$.

54. Mucci J, Hidalgo A, Mocetti E, Argibay PF, Leguizamon MS, Campetella $O$ : Thymocyte depletion in Trypanosoma cruzi infection is mediated by trans-sialidase-induced apoptosis on nurse cells complex. Proc Natl Acad Sci U S A 2002, 99(6):3896-390I.

55. Verinaud L, Da Cruz-Hofling MA, Sakurada JK, Rangel HA, Vassallo J, Wakelin D, Sewell HF, Camargo IJ: Immunodepression induced by Trypanosoma cruzi and mouse hepatitis virus type 3 is associated with thymus apoptosis. Clin Diagn Lab Immunol I998, 5(2): $|86-| 9 \mid$.

56. Reading PC, Moore JB, Smith GL: Steroid hormone synthesis by vaccinia virus suppresses the inflammatory response to infection. J Exp Med 2003, 197( (10): 1269-I278.

57. Moss B: Poxvirus entry and membrane fusion. Virology 2006, 344(I):48-54

58. Ichihashi Y, Dales S: Biogenesis of poxviruses: interrelationship between hemagglutinin production and polykaryocytosis. Virology I 97I, 46(3):533-543.

59. Law KM, Smith GL: A vaccinia serine protease inhibitor which prevents virus-induced cell fusion. J Gen Virol 1992, 73 ( $\mathbf{P t}$ 3):549-557.

60. Turner PC, Moyer RW: An orthopoxvirus serpinlike gene controls the ability of infected cells to fuse. I Virol 1992, 66(4):2076-2085

61. Zhou J, Sun XY, Fernando GJ, Frazer IH: The vaccinia virus K2L gene encodes a serine protease inhibitor which inhibits cellcell fusion. Virology 1992, I89(2):678-686.

62. Ortiz MA, Paez E: Identification of viral membrane proteins required for cell fusion and viral dissemination that are modified during vaccinia virus persistence. Virology 1994, 198(I): 155-168.

63. Earl PL, Moss B: Preparation of cell cultures and vaccinia virus stocks, p. 16.16.1-7. In F. M. Ausubelet al (ed.), Current protocols in molecular biology, vol. 2. New York, John Wiley \& Sons; 1997. 
64. Dong QG, Bernasconi S, Lostaglio S, De Calmanovici RW, MartinPadura I, Breviario F, Garlanda C, Ramponi S, Mantovani A, Vecchi A: A general strategy for isolation of endothelial cells from murine tissues. Characterization of two endothelial cell lines from the murine lung and subcutaneous sponge implants. Arterioscler Thromb Vasc Biol 1997, I7(8):1599-1604.

65. Lim YC, Garcia-Cardena G, Allport JR, Zervoglos M, Connolly AJ, Gimbrone MA Jr., Luscinskas FW: Heterogeneity of endothelial cells from different organ sites in T-cell subset recruitment. Am J Pathol 2003, 162(5): 1591-1601.

66. Poxvirus Bioinformatics Resource Center [http://www.poxvi rus.org]

Publish with Biomed Central and every scientist can read your work free of charge

"BioMed Central will be the most significant development for disseminating the results of biomedical research in our lifetime. "

Sir Paul Nurse, Cancer Research UK

Your research papers will be:

- available free of charge to the entire biomedical community

- peer reviewed and published immediately upon acceptance

- cited in PubMed and archived on PubMed Central

- yours - you keep the copyright

Submit your manuscript here:

http://www.biomedcentral.com/info/publishing_adv.asp
BiolMedcentral 